\title{
Artificial God Optimization - A Creation
}

\author{
${ }^{1}$ Satish Gajawada, ${ }^{2}$ Hassan M.H. Mustafa \\ ${ }^{1}$ Independent Inventor and Scientist \\ Founder and Father of Artificial Human Optimization Field \\ Alumnus, Indian Institute of Technology Roorkee \\ ${ }^{2}$ Faculty of Specified Education, Dept. of Educational Technology, \\ Banha University, Egypt \\ Grand Father of Artificial Human Optimization Field \\ satish.gajawada.iit@gmail.com; prof.dr.hassanmoustafa@gmail.com
}

\begin{abstract}
Nature Inspired Optimization Algorithms have become popular for solving complex Optimization problems. Two most popular Global Optimization Algorithms are Genetic Algorithms (GA) and Particle Swarm Optimization (PSO). Of the two, PSO is very simple and many Research Scientists have used PSO to solve complex Optimization Problems. Hence PSO is chosen in this work. The primary focus of this paper is on imitating God who created the nature. Hence the term "Artificial God Optimization (AGO)" is coined in this paper. AGO is a new field which is invented in this work. A new Algorithm titled "God Particle Swarm Optimization (GoPSO)" is created and applied on various benchmark functions. The World's first Hybrid PSO Algorithm based on Artificial Gods is created in this work. GoPSO is a hybrid Algorithm which comes under AGO Field as well as PSO Field. Results obtained by PSO are compared with created GoPSO algorithm. A list of opportunities that are available in AGO field for Artificial Intelligence field experts are shown in this work.

Keywords: Artificial Gods, Artificial God Optimization, Artificial God Computing, Computational Intelligence, Evolutionary Computing, Particle Swarm Optimization, Genetic Algorithms, Artificial Human Optimization, Bio-Inspired Computing, Nature Inspired Computing, Machine Learning, Artificial Intelligence.
\end{abstract}

\section{Introduction}

John Henry Holland proposed Genetic Algorithms in 1970's. From 1970's to till date, there are hundreds of Nature Inspired Optimization Algorithms proposed in literature. A Research scientist asked on Researchgate the following question in March 2015:

"Question: What are the various Nature Inspired Optimization Algorithms?"

Another Research Scientist replied the following algorithms as answer to the above question:

Answer: "The following is the list of various Nature Inspired Optimization Algorithms:

1. Genetic Algorithms (GA)

2. Simulated annealing (SA) 
3. Artificial immune systems (AIS)

4. Boids

5. Tabu Search

6. Memetic Algorithm (MA)

7. Ant Colony Optimization Algorithm (ACO)

8. Cultural Algorithms (CA)

9. Particle Swarm Optimization (PSO)

10. Self-propelled Particles

11. Differential Evolution (DE)

12. Bacterial Foraging Optimization

13. Harmony Search (HS)

14. MBO: Marriage in Honey Bees Optimization

15. Artificial Fish School Algorithm

16. Bacteria Chemotaxis (BC) Algorithm

17. Social Cognitive Optimization (SCO)

18. Artificial Bee Colony Algorithm

19. Bees Algorithm

20. Glowworm Swarm Optimization (GSO)

21. Honey-Bees Mating Optimization (HBMO) Algorithm

22. Invasive Weed Optimization (IWO)

23. Shuffled Frog Leaping Algorithm (SFLA)

24. Central Force Optimization

25. Intelligent Water Drops algorithm, or the IWD algorithm

26. River Formation Dynamics

27. Biogeography-based Optimization (BBO)

28. Roach Infestation Optimization (RIO)

29. Bacterial Evolutionary Algorithm (BEA)

30. Cuckoo Search (CS)

31. Firefly Algorithm (FA)

32. Gravitational Search Algorithm (GSA)

33. Group Search Optimizer

34. League Championship Algorithm (LCA)

35. Bat Algorithm

36. Bumble Bees Mating Optimization (BBMO) Algorithm

37. Eagle Strategy

38. Fireworks algorithm for optimization

39. Hunting Search

40. Altruism Algorithm

41. Spiral Dynamic Algorithm (SDA)

42. Strawberry Algorithm

43. Artificial Algae Algorithm (AAA)

44. Bacterial Colony Optimization

45. Differential Search Algorithm (DS

46. Flower pollination algorithm (FPA)

47. Krill Herd

48. Water Cycle Algorithm

49. Black Holes Algorithm

50. Cuttlefish Algorithm

51. Gases Brownian Motion Optimization 
52. Mine blast algorithm

53. Plant Propagation Algorithm

54. Social Spider Optimization (SSO)

55. Spider Monkey Optimization (SMO) algorithm

56. Animal Migration Optimization (AMO) Algorithm

57. Artificial Ecosystem Algorithm (AEA)

58. Bird Mating Optimizer

59. Forest Optimization Algorithm

60. Golden Ball

61. Grey Wolf Optimizer

62. Seed Based Plant Propagation Algorithm

63. Lion Optimization Algorithm (LOA): A Nature-Inspired Meta heuristic Algorithm

64. Optics Inspired Optimization (OIO)

65. The Raven Roosting Optimization Algorithm

66. Vortex Search Algorithm

67. Water Wave Optimization

68. collective animal behavior $C A B$ algorithm

69. Bumble bees mating optimization BBM

70. Flower Pollinated Algorithm

71. Chaos Optimization

72. Wind Driven Algorithm

73. Parliamentary optimization algorithm POA

74. Aritificial Chemical Process Algorithm

75. Aritificial Chemical Reaction Optimization Algorithm

76. Chemical Reaction Algorithm

77. Bull optimization algorithm

78. Elephent herding optimization (EHO)

79. Rain Optimization Algorithm".

From the above answer we can find that many Nature Inspired Optimization algorithms are proposed in literature till date. But there is not even a single algorithm which takes God (who created the nature) as Inspiration for creating innovative optimization algorithms. Hence a new field titled "Artificial God Optimization (AGO)" is invented in this work. AGO field is defined as follows:

Artificial Birds are the basic entities in Particle Swarm Optimization algorithm. Similarly, Artificial Gods are the basic entities in Artificial God Optimization (AGO). All the optimization algorithms which are proposed based on Artificial Gods will come under AGO Field. Each Artificial God corresponds to a point in search space. In addition to Artificial Gods there can be Artificial non-Gods in the population. Each Artificial nonGod corresponds to a point in the search space. Artificial non-Gods are less powerful than Artificial Gods.

Details related to God can be found in Ancient Hindu Religious Texts [1-2]. AGO Field concepts are applied to Particle Swarm Optimization (PSO) algorithm to create New AGO Field algorithms. PSO field details are given in articles [3-9]. Articles [10-28] show details related to Hybrid PSO Algorithms that are created by modifying PSO algorithm. Till date, there are no Artificial God Optimization Algorithms (AGO Algorithms) proposed in literature. This work makes use of this research gap and invents AGO field.

The rest of the article is organized as follows:

Particle Swarm Optimization algorithm is shown in Section 2. Section 3 shows "God Particle Swarm Optimization (GoPSO)". Results are explained in Section 4. Opportunities that are present in AGO Field are shown in Section 5. Conclusions are given in Section 6. 


\section{Particle Swarm Optimization}

Particle Swarm Optimization (PSO) was proposed by Kennedy and Eberhart in 1995. PSO is based on Artificial Birds. It has been applied to solve complex optimization problems.

In PSO, first we initialize all particles as shown below. Two variables pbest ${ }_{i}$ and gbest are maintained. pbest $t_{i}$ is the best fitness value achieved by $\mathrm{i}^{\text {th }}$ particle so far and gbest is the best fitness value achieved by all particles so far. Lines 4 to 11 in the below text helps in maintaining particle best and global best. Then the velocity is updated by rule shown in line no. 14 . Line 15 updates position of $\mathrm{i}^{\text {th }}$ particle. Line 19 increments the number of iterations and then the control goes back to line 4 . This process of a particle moving towards its local best and also moving towards global best of particles is continued until termination criteria will be reached.

Procedure: Particle Swarm Optimization (PSO)

1) Initialize all particles

2) iterations $=0$

3) do

4) for each particle i do

5) If $\left(f\left(x_{i}\right)<f\left(\right.\right.$ pbest $\left.\left._{i}\right)\right)$ then

6) $\quad$ pbest $_{i}=x_{i}$

7) end if

8) if $\left(f\left(\right.\right.$ pbest $\left._{i}\right)<f($ gbest $\left.)\right)$ then

9) $\quad$ gbest $=$ pbest $_{i}$

10) end if

11) end for

12) for each particle i do

13) for each dimension d do

14) $\quad v_{i, d}=w^{*} v_{i, d}+$ $\mathrm{C}_{1} *$ Random $(0,1) *\left(\right.$ pbest $\left._{\mathrm{i}, \mathrm{d}}-\mathrm{x}_{\mathrm{i}, \mathrm{d}}\right)$ $+\mathrm{C}_{2} *$ Random $(0,1)^{*}\left(\right.$ gbest $\left._{\mathrm{d}}-\mathrm{x}_{\mathrm{i}, \mathrm{d}}\right)$

19)

end for end for $\mathrm{x}_{\mathrm{i}, \mathrm{d}}=\mathrm{x}_{\mathrm{i}, \mathrm{d}}+\mathrm{v}_{\mathrm{i}, \mathrm{d}}$

20) while ( termination condition is false)

\section{God Particle Swarm Optimization}

The basic entities in the God Particle Swarm Optimization (GoPSO) are Artificial Gods and Artificial nonGods. Gods can always move in the search space. Whereas non-Gods can move in the search space only if non-God receives blessings of Gods. Based on random number generated and GodProbability, the particle is classified into either Artificial non-God or Artificial God. If a particle is classified as Artificial God then it will update position and velocity irrespective of anything. If particle is classified as Artificial nonGod then there are two cases. Based on random number generated and BlessingsOfGodProbability the particle is classified into Blessed non-God or not blessed non-God. Blessed non-God can move in search space and hence updates velocity and position. Not Blessed non-God cannot move in search space and hence doesn't update velocity and position. 
If the random number generated in line number 13 is less than GodProbability then particle is classified as Artificial God else it is classified as Artificial non-God. Lines 14-17 are executed by God. Lines 19-26 are executed by non-God. If the random number generated is less than BlessingsOfGodProbability then the non-God is blessed else it is not blessed non-God. Blessed non-God executes lines 20-23. Hence velocity and position are updated for Blessed non-God. Line number 25 is blank. Hence Not Blessed non-God is blocked and does nothing. The same procedure is repeated for all particles in first generation.

In second generation, line number 13 is again executed. Particle classified as God in first generation can be classified as non-God in second generation. Particle classified as non-God in first generation can be classified as God in second generation. Similarly, in second generation, line number 19 is again executed. So, whether non-God receives blessings of God or not is dependent on the random number generated and BlessingsOfGodProbability. The remaining procedure is same as that of first generation.

Procedure: God Particle Swarm Optimization (GoPSO)

1) Initialize all particles

2) iterations $=0$

3) do

4) for each particle i do

5) If $\left(f\left(x_{i}\right)<f\left(\right.\right.$ pbest $\left.\left._{i}\right)\right)$ then

6)

7)

8)

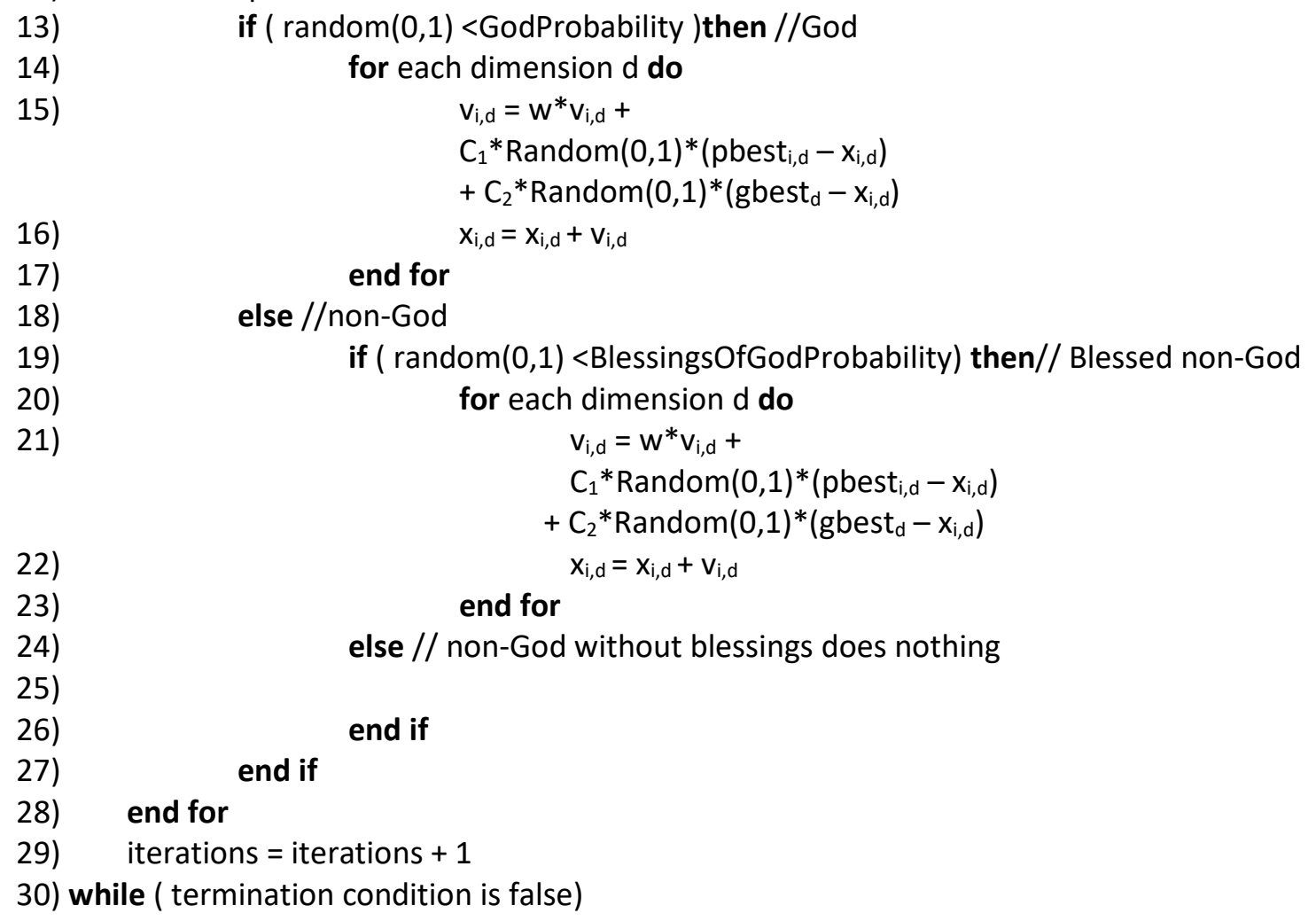

30) while ( termination condition is false) 


\section{Results}

Benchmark Functions used in this paper are taken from [29]. The proposed God Particle Swarm

Optimization (GoPSO) is applied on five benchmark functions. Results obtained are compared with PSO.

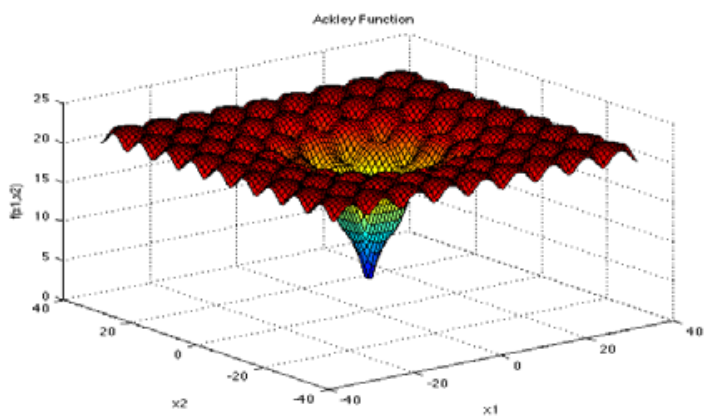

Figure 1. Ackley Function

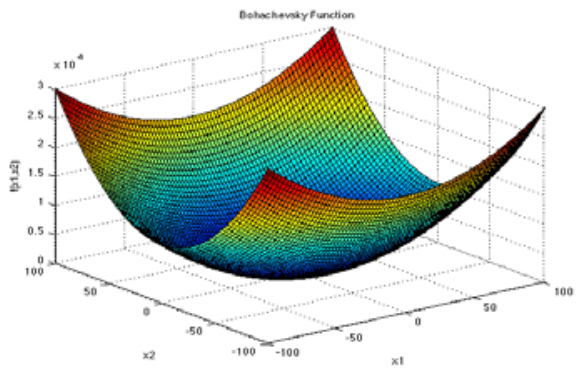

Figure 3. Bohachevsky Function

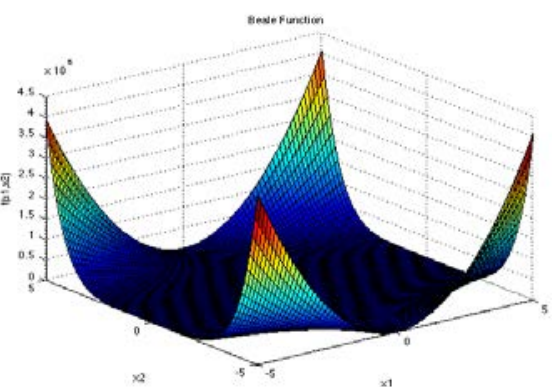

Figure 2. Beale Function

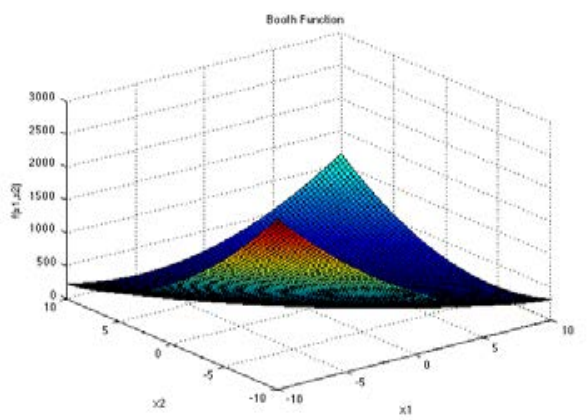

Figure 4. Booth Function

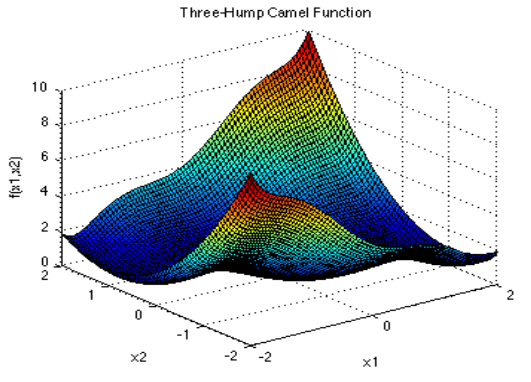

Figure 5. Three-Hump Camel Function

Table 1. Overall Result

\begin{tabular}{|c|c|c|}
\hline Benchmark Function / Algorithm & GoPSO & PSO \\
\hline Ackley Function & & \\
\hline Beale Function & & \\
\hline Bohachevsky Function & & \\
\hline Booth Function & & \\
\hline Three-Hump Camel Function & & \\
\hline
\end{tabular}


In Table 1 Green represents Performed well. Red represents didn't performed well. Blue represents performed between well and not well. From Table 1 we can see that both GoPSO and PSO performed well on all benchmark functions.

\section{Interesting Opportunities in Artificial God Optimization Field}

The following are the opportunities in Artificial God Optimization field (AGO field) for experts in Artificial Intelligence field:

(1) International Institute of Artificial God Optimization, Hyderabad, INDIA

(2) Indian Institute of Technology Roorkee Artificial God Optimization Labs, IIT Roorkee

(3) Foundation of Artificial God Optimization, New York, USA.

(4) IEEE Artificial God Optimization Society

(5) ELSEVIER journals in Artificial God Optimization

(6) Applied Artificial God Optimization - A New Subject

(7) Advanced Artificial God Optimization - A New Course

(8) Invited Speech on "Artificial God Optimization" in world class Artificial Intelligence Conferences

(9) A Special issue on "Artificial God Optimization" in a Springer published Journal

(10) A Seminar on "Recent Advances in Artificial God Optimization" at Technical Festivals in colleges

(11) International Association of Artificial God Optimization (IAAGO)

(12) Transactions on Artificial God Optimization (TAGO)

(13) International Journal of Artificial God Optimization (IJAGO)

(14) International Conference on Artificial God Optimization (ICAGO)

(15) www.ArtificialGodOptimization.com

(16) B.Tech in Artificial God Optimization

(17) M.Tech in Artificial God Optimization

(18) PhD in Artificial God Optimization

(19) PostDoc in Artificial God Optimization

(20) Artificial God Optimization Labs

(21) To become "Father of Artificial God Optimization" field

\section{Conclusions}

Artificial God Optimization field (AGO field) is invented in this work. A novel God Particle Swarm Optimization (GoPSO) is created in this work. PSO and GoPSO performed well on all benchmark functions. The invented AGO field comes under Artificial God Computing Field. As mentioned in arXiv pre-print, arXiv: 1903.12011 [cs.NE], there is scope for many PhD's and PostDoc's in Artificial Human Optimization field. It is also mentioned that there are millions of articles possible in AHO field. Similarly, we can easily prove that AGO field invented in this work has millions of opportunities which are yet to be explored by Research Scientists across the globe.

\section{ACKNOWLEDGEMENTS}

The authors of this work would like to thank the following Editorial Members of "Transactions on Machine Learning and Artificial Intelligence (TMLAI)" for accepting our innovative invention titled Artificial God Optimization Field (AGO Field):

o Professor Er Meng Joo, School of Electrical and Electronic Engineering, Nanyang Technological University, Singapore 
o Professor Djamel Bouchaffra, Department of Mathematics and Computer Science, Grambling State University, Louisiana., United States

o Prof Bhavani Thuraisingham, Department of Computer Science, Erik Jonsson School of Engineering and Computer Science, The University of Texas at Dallas, United States

o Professor Dong-Hee Shin, Department of Interaction Science, Social Computing Institute, Sungkyunkwan University, Seoul, Korea, Republic of

o Professor Filippo Neri, Professor of Computer Information Systems, Faculty of Information \& Communication Technology, Dar Guzeppi Zahra, University of Malta, Malta

o Prof Mohamed A Zohdy, Department of Electrical and Computer Engineering, Oakland University, United States

o Professor Wee SER, Associate Professor Director, VALENS Research Centre, School of Electrical and Electronic Engineering; Program Director (MISA), Nanyang Institute of Technology in Medicine and Health Nanyang Technological University, Singapore

o Professor Liang Yanchun, Deputy Dean of College of Computer Science, Jilin University, China

o Professor Julia Johnson, Dept. of Mathematics \& Computer Science Laurentian University, Sudbury, Ontario, Canada

o Professor Farouk Yalaoui, Institut Charles Dalaunay, University of Technology of Troyes, France

o Professor Jai N Singh, Department of Mathematics and Computer Science, Barry University, Miami Shores, Florida, United States

o Dr Kyriakos G Vamvoudakis, Dept of Electrical and Computer Engineering, University of California Santa Barbara, United States

o Dr Zezhi Chen, School of Computing and Information Systems; Faculty of Science, Engineering and Computing; Kingston University London, United Kingdom

o Dr Luis Rodolfo Garcia, College of Science and Engineering, Texas A\&M University, Corpus Christi, United States

o Dr Hafiz M. R. Khan, Associate Professor \& Graduate Program Director, Department of Biostatistics, Florida International University, United States

o Dr Xiaocong Fan, School of Engineering, Behrend College, The Pennsylvania State University, United States

o Dr Chen Yanover, Machine Learning for Healthcare and Life Sciences IBM Haifa Research Lab, United States

o Dr Vandana Janeja, Information Systems Department, University of Maryland, Baltimore, United States

o Dr Nikolaos Georgantas, Senior Research Scientist at INRIA, Paris-Rocquencourt, France

o Dr Zeyad Al-Zhour, College of Engineering, The University of Dammam, Saudi Arabia

o Dr Zdenek Zdrahal, Senior Research Fellow in Artificial Intelligence, Knowledge Media Institute, The Open University, Milton Keynes MK7 6AA, United Kingdom

o Dr Steve S. H. Ling, University of Technology, Sydney, Australia

o Dr Marianne Hoogeveen, Arena Analytics, United States

o Dr Hooshang Hemami, Dept. of Electrical and Computer Engineering The Ohio State University Columbus, Ohio 43210, United States

o Dr Hiroyuki Utsunomiya, University of Tokyo, Japan

\section{REFERENCES}

[1] Veda Vyasa, Srimad Bhagavatha Purana. Ancient Hindu Religious Text. 
[2] Veda Vyasa, Bhagavad Gita. Ancient Hindu Religiuos Text.

[3] Saptarshi Sengupta, Sanchita Basak, Richard Alan Peters II. Particle Swarm Optimization: A survey of historical and recent developments with hybridization perspectives. https://arxiv.org/abs/1804.05319, 2018.

[4] Yudong Zhang, Shuihua Wang, and Genlin Ji, "A Comprehensive Survey on Particle Swarm Optimization Algorithm and Its Applications," Mathematical Problems in Engineering, vol. 2015, Article ID 931256, 38 pages, 2015. https://doi.org/10.1155/2015/931256.

[5] M. R. AlRashidi, M. E. El-Hawary. A Survey of Particle Swarm Optimization Applications in Electric Power Systems. IEEE Transactions on Evolutionary Computation. Volume 13, Issue 4, August 2009.

[6] Sharandeep Singh. A Review on Particle Swarm Optimization Algorithm. International Journal of Scientific \& Engineering Research, Volume 5, Issue 4, April-2014.

[7] T. Saravanan and V. Srinivasan. Overview of Particle Swarm Optimization. Indian Journal of Science and Technology, Vol 8(32), November 2015.

[8] Muhammad Imran, Rathiah Hashim, Noor Elaiza Abd Khalid.An Overview of Particle Swarm Optimization Variants. Procedia Engineering. Elsevier.Volume 53, Pages 491-496, 2013.

[9] Riccardo Poli, James Kennedy, Tim Blackwell. Particle swarm optimization - An overview. Swarm Intelligence. Volume 1, Issue 1, pp 33-57, Springer, 2007.

[10] Liu H, Xu G, Ding GY, Sun YB, "Human behavior-based particle swarm optimization", The Scientific World Journal, 2014.

[11] Ruo-Li Tang, Yan-Jun Fang, "Modification of particle swarm optimization with human simulated property", Neurocomputing, Volume 153, Pages 319-331, 2015.

[12] Muhammad Rizwan Tanweer, Suresh Sundaram, "Human cognition inspired particle swarm optimization algorithm", 2014 IEEE Ninth International Conference on Intelligent Sensors, Sensor Networks and Information Processing (ISSNIP), 2014.

[13] M.R. Tanweer, S. Suresh, N. Sundararajan, "Self regulating particle swarm optimization algorithm", Information Sciences: an International Journal, Volume 294, Issue C, Pages 182-202, 2015.

[14] Satish Gajawada. "POSTDOC : The Human Optimization", Computer Science \& Information Technology (CS \& IT), CSCP, pp. 183-187, 2013.

[15] Satish Gajawada. "CEO: Different Reviews on PhD in Artificial Intelligence", Global Journal of Advanced Research, vol. 1, no.2, pp. 155-158, 2014.

[16] Satish Gajawada. "Entrepreneur: Artificial Human Optimization". Transactions on Machine Learning and Artificial Intelligence, Volume 4 No 6 December (2016); pp: 64-70

[17] Satish Gajawada. "Artificial Human Optimization - An Introduction", Transactions on Machine Learning and Artificial Intelligence, Volume 6, No 2, pp: 1-9, April 2018

[18] Satish Gajawada. "An Ocean of Opportunities in Artificial Human Optimization Field", Transactions on Machine Learning and Artificial Intelligence, Volume 6, No 3, June 2018 
Satish Gajawada, Hassan M.H. Mustafa; Artificial God Optimization - A Creation, Transactions on Machine Learning and Artificial Intelligence, Volume 7 No 6 December, (2019); pp: 1-10

[19] Satish Gajawada. "25 Reviews on Artificial Human Optimization Field for the First Time in Research Industry", International Journal of Research Publications, Vol. 5, no. 2, United Kingdom.

[20] Satish Gajawada and Hassan M. H. Mustafa, "Collection of Abstracts in Artificial Human Optimization Field", International Journal of Research Publications, Volume 7, No 1, United Kingdom, 2018.

[21] Satish Gajawada, Hassan M. H. Mustafa, HIDE : Human Inspired Differential Evolution - An Algorithm under Artificial Human Optimization Field, International Journal of Research Publications (Volume: 7, Issue: 1), http://ijrp.org/paper-detail/264

[22] Satish Gajawada, Hassan M. H. Mustafa , Artificial Human Optimization - An Overview. Transactions on Machine Learning and Artificial Intelligence, Volume 6, No 4, August 2018.

[23] Satish Gajawada, Hassan M. H. Mustafa, Testing Multiple Strategy Human Optimization based Artificial Human Optimization Algorithms, Computer Reviews Journal, vol. 1, no.2, 2018.

[24] Satish Gajawada, Hassan M. H. Mustafa. Hybridization Concepts of Artificial Human Optimization Field Algorithms Incorporated into Particle Swarm Optimization. International Journal of Computer Applications 181(19):10-14, September 2018.

[25] Satish Gajawada, Hassan M. H. Mustafa (2018). An Artificial Human Optimization Algorithm Titled Human Thinking Particle Swarm Optimization. International Journal of Mathematical Research, 7(1): 18-25. DOI: 10.18488/journal.24.2018.71.18.25

[26] Satish Gajawada, Hassan Mustafa: Novel Artificial Human Optimization Field Algorithms - The Beginning. CoRR abs/1903.12011(2019)

[27] Satish Gajawada, Hassan M. H. Mustafa: Ten Artificial Human Optimization Algorithms. Transactions on Machine Learning and Artificial Intelligence, Volume 7, No 3, June 2019.

[28] https://www.sfu.ca/ ssurjano/optimization.html 